\title{
GAMBARAN PERSONAL HIGIENE DAN KEADAAN SANITASI INDUSTRI TEMPE UD ANDIKA PANGURIPAN DI DESA TAGTAG KAJA KECAMATAN DENPASAR UTARA TAHUN 2019
}

\author{
Ni Luh Putu Ayu Suwandewi ${ }^{1}$ \\ Ni Ketut Rusminingsih ${ }^{2}$, I Nyoman Purna ${ }^{3}$
}

\begin{abstract}
AndikaPanguripan trading business is a home industry that produces tempe. AndikaPanguripan's trading business is in TagtagKaja Village, Singasari Utara street, Uma Punggul II alley No. 31, which was established in 2010, has 10 employees.The purpose of the study was to determine the description of personal hygiene and the sanitation conditions of AndikaPanguripan Trade Business tempe in TagtagKaja Village, North Denpasar Subdistrict in 2019. The research method used is descriptive research method with cross sectional approach.Data collection is done by observation and interview. Examination is carried out with observation sheets on the state of sanitation (buildings and sanitation facilities, food sanitation) and personal hygiene.The collected data is processed and presented in the form of tables. The results of this study are that the condition of buildings and sanitation facilities is categorized as moderate with 9 (43\%), food sanitation is categorized as being moderate with a score of 13 (62\%), sanitation conditions are categorized as being moderate with a score of $22(52 \%)$ and personal hygiene of employees categorized as being moderate with a score of 6 (60\%). Conclusions from the results of research on the state of sanitation, food, building and personal hygiene AndikaPanguripan trading business is included in the medium category.Suggestion is to make repairs to buildings and sanitation facilities at tempe processing sites, maintain cleanliness of tempe processing facilities, and employees to apply personal hygiene while working.
\end{abstract}

Keywords: personal hygiene and sanitation

\section{Pendahuluan}

Pangan merupakan segala sesuatu yang berasal dari sumber hayati produk pertanian, perkebunan, kehutanan, perikanan, peternakan, perairan dan air, baik yang diolah yang diperuntukan sebagai makanan atau minuman bagi konsumsi manusia, termasuk bahan tambahan pangan, bahan baku pangan dan bahan baku lainnya yang digunakan dalam proses penyiapan, pengolahan,dan pembuatan makanan atau minuman.(1)

Higiene adalah upaya kesehatan dengan cara memelihara dan melindungi kebersihan individu subjeknya. Untuk mencegah kontaminasi makanan dengan zat-zat yang dapat mengakibatkan gangguan kesehatan diperlukan penerapan sanitasi makanan.(2) 
Sanitasi makanan adalah salah satu usaha pencegahan yang menitik beratkan kegiatan dan tindakan yang perlu untuk membebaskan makanan dan minuman dari segala bahaya yang dapat mengganggu kesehatan, mulai dari makanan diproduksi, selama proses pengolahan, penyimpanan dan pengangkutan, sampai pada saat makanan dan minuman tersebut siap untuk dikonsumsi oleh masyarakat atau konsumen. Sanitasi makanan bertujuan untuk menjamin keamanan dan kemurnian makanan, mencegah konsumen dari penyakit, mencegah penjualan makanan merugikan pembeli mengurangi kerusakan, atau pemborosan makanan.(3)

Industri pengolahan kedelai adalah usaha atau kegiatan yang memanfaatkan kedelai sebagai bahan baku utama yang tidak bisa digantikan dengan bahan lain. (4)

Tempe merupakan makanan yang terbuat biji kedelai atau beberapa bahan lain yang diproses melalui fermentasi dari apa yang secara umum dikenal sebagai "ragi tempe". Melalui proses fermentasi, biji kedelai mengalami proses penguraian menjadi senyawa sederhana sehingga mudah dicerna. (5)

Berdasarkan hasil penelitian (Suhartono,2008) (6) yang dilakukan dilokasi pabrik tempe yaitu di Kecamatan Sumber Jaya sebanyak 3 pengrajin, Way Tenong sebanyak 1 pengrajin, Balik Bukit sebanyak 7 pengrajin dan Pesisir Tengah sebanyak 4 pengrajin menunjukan bahwa, pada umumnya pengendalian sanitasi lingkungan di sekitar pabrik masih buruk dengan rata-rata capaian $28.57 \%$.

Berdasarkan pengamatan sementara yang dilakukan di Industri Tempe UD. Andika Panguripan terdapa 10 orang karyawan dalam bekerja karyawan belum menerapkan hygiene sanitasi dalam mengolah makanan yaitu karyawan tidak menggunakan alat pelindung diri, alat produksi terlihat kotor, lantai tidak kedap air, serta tempat tinggal karyawan menjadi satu dengan bangunan industri tempe UD Andika Panguripan.

UD. Andika Panguripan memiliki luas bangunan 4 are dengan memproduksi olahan kedelai sebanyak 50kg/hari. UD. Andika Panguripan berlokasi di Jalan Singasari Utara memiliki pelanggan di berbagai daerah khususnya Denpasar.

\section{Hasil Pengamatan berdasarkan variabel penelitian}

Penelitian ini dilaksanakan pada tanggal 11 dan 12 April 2019 di UD. 
Andika Panguripaan dengan mengunakan lembar observasi, dan hasil yang didapat sebagai berikut:

a. Hasil penilaian keadaan sanitasi makanan pada UD. Andika Panguripan

Berdasarkan penilaian yang telah dilakukan pada UD. Andika Panguripan sanitasi makanan mendapatkan skor 13 dengan persentase $62 \%$ sehingga dikategorikan sedang.

b. Hasil penilaian keadaan bangunan dan fasilitas sanitasi UD. Andika Panguripan.

Berdasarkan penilaian yang telah dilakukan pada UD Andika Panguripan keadaan bangunan dan fasilitas sanitasi mendapatkan skor 9 dengan persentase 43\% sehingga dikategorikan sedang.

Dari hasil penelitian sanitasi makanan, keadaan bangunan dan fasilitas sanitasi pada UD. Andika Panguripan, maka didapatkan hasil keadaan sanitasi UD. Andika Panguripan pada tabel 1 berikut:

Tabel 1

Hasil Penilaian Keadaan Sanitasi UD. Andika Panguripan

\begin{tabular}{clccc}
\hline \hline NO & Item Penilaian & Skor & Persentase(\%) & Kategori \\
\hline \hline 1 & $\begin{array}{l}\text { Keadaan Sanitasi } \\
\text { Makanan }\end{array}$ & 13 & 62 & Sedang \\
2 & $\begin{array}{l}\text { Keadaan Bangunan } \\
\text { dan fasilitas Sanitasi }\end{array}$ & 9 & 43 & Sedang \\
\hline
\end{tabular}

c. Hasil penilaian personal higiene karyawan

Berdasarkan penilaian personal higiene UD. Andika Panguripan dari 10 karyawan menunjukkan bahwa terdapat enam karyawan dikategorikan sedang dengan persentase $60 \%$ dan empat karyawan lainnya dikategorikan kurang dengan persentase 40\%. Sehingga penilaian personal higiene karyawan
UD. Andika Panguripan dikategorikan sedang.

\section{Pembahasan}

\section{Keadaan sanitasi}

Dari hasil penilaian keadaan sanitasi makanan, bangunan dan fasilitas sanitasi didapatkan keadaan sanitasi dengan jumlah skor 22 dikategorikan sedang, berdasarkan pada Peraturan Menteri Kesehatan Republik Indonesia Nomor 1096/MENKES/PER/VI/2011 
tentang higiene sanitasi jasaboga. Hal ini disebabkan karena bahan makanan dan peralatan ditempatkan di tempat terbuka

yang tidak terlindung dari vektor, pengangkutan bahan makanan terlihat dinding dan atap berdebu karena bangunan jarang dibersihkan, lantai becek dan licin terkena tumpahan air, toilet berdampingan dengan ruang kerja, tempat sampah menggunakan ember tanpa tutup.

\section{Personal higiene karyawan}

Dari hasil observasi yang telah dilakukan terdapat 6 karyawan dikategorikan sedang dengan persentase $60 \%$ dan 4 karyawan lainnya dikategorikan kurang dengan persentase $40 \%$, berdasarkan Peraturan Menteri Kesehatan Republik Indonesia Nomor 1096/MENKES/PER/VI/2011 tentang higiene sanitasi jasaboga. Hal ini disebabkan karena karyawan tidak memiliki sertifikat kursus higiene sanitasi makanan dikarenakan karyawan belum pernah mengikuti kursus tentang higiene sanitasi makanan, terdapat 4 orang karyawan yang pernah mengidap typus dalam satu tahun terakhir, karyawan belum pernah melakukan pemeriksaan kesehatan, karyawan tidak menggunakan pakaian kerja menggunakan mobil bak terbuka dapat menyebabkan debu dan kotoran mengontaminasi bahan makanan, tempat pencucian peralatan yang menjadi satu dengan tempa cuci tangan, sedangkan pada bangunan dikarenakan suhu ruangan yang panas, karyawan tidak menggunakan sarung tangan (handscoon), sepatu boots, celemek, dan tutup rambut dikarenakan pengelola tidak menyediakan sarung tangan (handscoon), sepatu boots, masker, celemek, dan tutup rambut.

Menurut Depkes RI (2006) hendaknya tangan selalu dicuci sebelum bekerja, sesudah menangani bahan makanan kotor, mentah atau terkontaminasi, setelah dari kamar kecil, setelah tangan digunakan untuk menggaruk, batuk atau bersin dan setelah makanan atau merokok. Kebersihan tangan penjamah makanan yang bekerja mengolah dan memproduksi pangan sangat penting kerena itu perlu mendapatkan perhatian khusus.

\section{Keadaan bangunan dan fasilitas sanitasi}

Dari hasil penilaian keadaan bangunan dan fasilitas sanitasi didapatkan skor 9 dengan persentase 43\% dikategorikan sedang, berdasarkan Peraturan Menteri Kesehatan Republik 
Indonesia Nomor

1096/MENKES/PER/VI/2011 tentang

higiene sanitasi jasaboga. Hal ini disebabkan karena bangunan kurang terawat karena jarang dibersihkan dapat dilihat dari dinding dan langit-langit yang berdebu, terdapat lantai becek terkena tumpahan air pada beberapa tempat dapat menyebabkan orang tergelincir, bagian dinding yang terkena air tidak dilapisi dengan bahan kedap air, tidak memiliki cerobong asap, toilet terhubung dengan ruang kerja, tempat cuci tangan dan tempat cuci peralatan tidak terpisah, tempat sampah menggunakan ember tanpa tutup, hal ini dikarenakan kurangnya pengetahuan pengelola tentang persyaratan higiene dan sanitasi tempat industri.

\section{Simpulan}

1. Keadaan sanitasi pada UD. Andika Panguripan termasuk dalam kategori sedang.

2. Personal higiene karyawan UD. Andika Panguripan termasuk dalam kategori sedang dengan persentase $60 \%$.

3. Kondisi bagunan dan fasilitas sanitasi UD. Andika Panguripan termasuk dalam kategori sedang dengan persentase $43 \%$.

\section{Saran}

1. Bagi Pengelola Industri

Agar karyawan membersihkan tempat pengolahan setiap selesai melakukan kegiatan pengolahan tempe, pengelola menyediakan sarung tangan (handscoon), sepatu boots, masker, celemek, tutup rambut,dan memeriksakan kesehatan karyawan sekurangkurangnya satu tahun sekali, sedangkan dalam jangka panjang melakukan perbaikan pada bangunan dan fasilitas sanitasi

\section{Bagi Karyawan}

Karyawan meningkatkan kesadaran untuk mau dan tetap menerapkan personal higiene dalam bekerja dan tidak malas untuk menerapkan personal higiene setiap bekerja sebagai penjamah makanan.

\section{DAFTAR PUSTAKA}

1. RI. Undang-undang Republik Indonesia Nomor 18 tahun . Tentang Pangan. Jakarta: Jakarta; 2012.

2. RI DR. Sanitasi Makanan dan Minuman. Jakarta: Depkes RI; 2006.

3. Sumantri. Kesehatan 
Jurnal Kesehatan Lingkungan Vol.9 No.2 Oktober 2019: 109-114

Lingkungan. Edisi keti. Jakarta:

Kharisma Putra Utama; 2015.

4. Indonesia. MLHR. Peraturan

Menteri Lingkungan Hidup

Republik Indonesia. Permen LH

No. 5 Tahun 2014 Tentang Baku

Mutu Air Limbah. Jakarta:

Menteri Lingkungan Hidup

Republik Indonesia.; 2014.

5. Badan Standardisasi Nasional.

Tempe : Persembahan Indonesia
Untuk Indonesia. Jakarta: Badan

Standardisasi Nasiona; 2012. 1-

$10 \mathrm{p}$.

6. Suhartono dkk. Penerapan

Prinsip-Prinsip Mutu Dan

Keamanan Pangan Tempe Di

Kabupaten Lampung Barat.

Lampung Barat; 2008. 